\title{
El modelo de justicia transicional y su relación con la justicia retributiva en Colombia'
}

\section{The transitional justice model and its relationship with remuneration justice in Colombia}

\author{
Henry Torres Vásquez². \\ Claudia Rocío Echeverry Beltrán ${ }^{3}$ \\ Danilo Alfredo Ortiz Vargas ${ }^{4}$ \\ Universidad Pedagógica y Tecnológica de Colombia
}

\section{RESUMEN}

En este trabajo se analiza la justicia transicional como una forma diferente de hacer justicia, que se aplica de manera excepcional y durante un determinado tiempo. Históricamente se ha entendido como el conjunto de acciones de todo tipo a las que el Estado acude para superar situaciones largas de conflicto armado, y en las que la solución es el diálogo entre partes.

Es una justicia muy distinta al modelo clásico de derecho penal ordinario, el cual es se emplea en todo tiempo y lugar del territorio nacional; es claro

\footnotetext{
$1 \quad$ Artículo requisito para optar al título de Magíster en Derechos Humanos de la Universidad Pedagógica y Tecnológica de Colombia. Este trabajo pertenece a los avances de la investigación "La justicia transicional colombiana frente al derecho penal internacional" dentro del grupo de investigación "Derecho penal y DIH" de la Universidad Pedagógica y Tecnológica de Colombia. 2 Doctor en Sistema penal de la Universidad Jaime I de Castellón, España. Tesis doctoral: análisis del terrorismo de Estado, máxima calificación "Cum Laude" por unanimidad, 2008. Abogado de la Universidad Nacional de Colombia, Licenciado en derecho en España. Par académico e investigador Asociado (1) de Colciencias. Profesor de planta de Derecho penal de la Universidad Pedagógica y Tecnológica de Colombia. Líder del grupo de investigación Derecho Penal y DIH de la Universidad Pedagógica y Tecnológica de Colombia. ORCID http://orcid.org/0000-0002-5299-8269. Henry Torres Vásquez, P.h.D. - Citas de Google Académico

3 Abogada egresada de la Universidad Libre, maestranda del programa de Maestría en Derechos Humanos de la Universidad Pedagógica y Tecnológica de Colombia, sede Bogotá. ORCID: http://orcid.org/0000-0002-0458-1768 Correo: creabogado@gmail.com

$4 \quad$ Abogado. Magister DD.HH Docente Facultad Derecho UPTC- danilo.ortiz@uptc.edu.co Doctorando Estudios Migratorios U. Jaén daov0001@red.ujaen.es Fundador y director REDUCARed.Org REDUCARed@gmail.com
} 
que, a pesar de existir una jurisdicción especial para la paz, el derecho penal sigue vigente. Aun así, a raíz del Acuerdo de Paz entre las Farc Ep y el gobierno de Juan Manuel Santos en la actualidad la preferencia la tiene la Jurisdicción Especial para la Paz para conocer conductas criminales cometidas con anterioridad al 1 de diciembre de 2016 perpetradas con ocasión y en desarrollo del conflicto armado interno en Colombia.

Este artículo se enfoca en analizar las tensiones y estudia si se complementan la justicia restaurativa en la justicia penal convencional y la justicia de transición y su componente de justicia restaurativa, modelos actualmente vigentes en Colombia. Se concluye que no existe tensión y que ambas formas de justicia integran un hibrido que es un modelo de justicia específicamente destinada a solventar los problemas derivados de haber vivido décadas de conflicto armado no internacional en los que hubo millones de víctimas y en las que el derecho penal ha resultado insignificante.

\section{PALABRAS CLAVE:}

Conflicto armado interno, derecho penal, justicia retributiva, justicia transicional, acuerdo de paz en Colombia.

\section{ABSTRACT.}

In this paper, transitional justice is analyzed as a different way of doing justice, which is applied exceptionally and for a certain time. Historically, it has been understood as the set of actions of all kinds to which the State goes to overcome long situations of armed conflict, and in which the solution is dialogue between the parties.

It is a very different kind of justice from the classic model of ordinary criminal law, which is a right that is used in all times and places in the national territory; It is clear that, despite the existence of a special jurisdiction for peace, criminal law is still in force. Even so, as a result of the peace agreement between the FARC EP and the government of Juan Manuel Santos, the preference currently goes to the Special Jurisdiction for Peace to hear criminal conduct committed prior to December 1, 2016 perpetrated on the occasion and in development of the internal armed conflict in Colombia.

This article focuses on analyzing tensions and studies whether restorative justice complements conventional criminal justice and transitional justice and its restorative justice component, models currently in force in Colombia. It is concluded that there is no tension and that both forms of justice integrate a hybrid that is a model of justice specifically designed to solve the problems derived from having lived through decades of non-international armed conflict in which there were millions of victims and in which the law criminal has been insignificant.

\section{KEYWORDS:}

Internal armed conflict, criminal law, retributive justice, transitional justice, peace agreement in Colombia.

\section{METODOLOGÍA.}

A partir de una metodología análisis síntesis en la que se hizo un importante barrido de fuentes secundarias sobre los diversos tratamientos llevados a cabo en modelos de justicia transicional y de justicia retributiva que es la que rige el derecho penal lo que unido a un estudio sobre la dogmática penal en Colombia y de la justicia transicional se pudo establecer los resultados que aquí se exponen relativos a la articulación y tensiones entre uno y otro modelo de justicia. Esta metodología permitió allegar la información suficiente para el logro de los objetivos ya señalados. 


\section{APROXIMACIÓN AL PROBLEMA DE INVESTIGACIÓN}

La impunidad y la consecuente necesidad de justicia para superar los hechos que desencadenan el surgimiento de las guerrillas en Colombia y especialmente superar la violencia por ellos cometida en décadas junto a los delitos cometidos por el mismo Estado en su persecución, unido a la aparición de grupos de paramilitares que en ocasiones se aliaron con el ejército y la policía y llevaron a cabo miles de crímenes. Todos estos delitos y ante las graves infracciones a derechos humanos (DDHH) y al Derecho Internacional Humanitario (DIH) se requería de un Acuerdo de Paz. Después de muchos intentos por parte de diferentes gobiernos se llegó a un acuerdo en el año 2016 entre las Fuerzas Armadas Revolucionarias de Colombia- Ejército del Pueblo (Farc Ep) y el gobierno de Juan Manuel Santos Calderón.

De ese modo se espera superar la violencia masiva presente y futura dentro del marco del conflicto armado interno colombiano lo que se presenta como la mejor solución a un eternizado problema de violencia masificada y extrema.

La violencia en Colombia junto a la corrupción han sido serios problemas que han trascendido históricamente. Por esta y otras razones, el derecho penal convencional no ha podido hacer justicia ni superar la inconformidad social. Con el advenimiento de la justicia de transición se intentan superar otras formas de criminalidad, la que produjo las Farc Ep, agentes estatales y algunos terceros civiles, los que durante años cometieron toda suerte de conductas punibles que sin lugar a dudas son crímenes de lesa humanidad. En ese contexto de crímenes junto a una cada vez más extensa corrupción y con una enorme cantidad de impunidad se establece después de muchos intentos, una justicia transicional que a pesar de tener muchos partidarios ha provocado cierto malestar en otra parte de la sociedad. El gobierno no ha llevado a cabo un ejercicio mediático y real de asimilación de un modelo de justicia de transición en medio de una sociedad ancestralmente ligada al derecho penal, y por tanto esta no ha visto con buenos ojos una justicia de corte restaurativo. Muy por el contrario, quienes no creen en la paz consideran con mucha ayuda de medios de comunicación pro gobiernistas que este tipo de justicia es una gran fuente de impunidad. Bajo estos argumentos, hay quienes afirman que es necesario recurrir a que tribunales internacionales hagan justicia en Colombia bajo el imperativo de la llamada justicia universal, la que se entiende como la posibilidad de que cualquier país del mundo pueda llevar a cabo un juicio penal por conductas acaecidas en Colombia (Torres, 2013, p. 101). De aquí surge el interrogante ¿Se complementan la justicia penal y la justicia transicional actualmente vigente en Colombia?

\section{INTRODUCCIÓN.}

La justicia penal y la justicia retributiva que le es atribuida han sido tradicionales, es así como la Constitución política y la ley son fuentes primarias del derecho penal lo que crea en la sociedad una consciencia de estar, en materia penal, representados muy bien por el Estado y muy conformes con las normas penales que este expide. No obstante, en la actualidad hay otro tipo de justicia, como es la justicia restaurativa que se preocupa más por la víctima y que deja de lado la pena y que convierte a víctima y victimario en verdaderos protagonistas en materia penal. Así se encuentra establecido en la carta política y en la ley penal. Esta justicia nació en Colombia de la justicia transicional la que más adelante veremos a su vez surgió del Acuerdo de Paz.

Mientras que la ley penal, como no puede ser de otro modo, está vigente; la justicia transicional con sus mecanismos de enfoque restaurativo se empezó a aplicar y al ser autónoma y transitoria es obvio que la justicia transicional tenga un 
periodo de vigencia (en Colombia15 años) ya que como su nombre lo indica es una justicia que opera para superar un periodo de guerra, lo que supone exactamente una transición entre la guerra y la pacificación. Esta particular situación admite diversas formas de concertar política y jurídicamente aspectos relativos fundamentalmente al resarcimiento de los perjuicios a las víctimas y a la clase y formas de castigo a los victimarios. eta se aplica a quienes hayan cometido conductas punibles en medio del conflicto armado colombiano antes del 1 de diciembre de 2016. A partir de allí la competencia es de la justicia penal ordinaria.

Como señala Lyons "el término justicia transicional o "justicia de transición" estuvo referido en sus orígenes a los esfuerzos de justicia en lo que es, de manera esencial, un proceso de transición puramente político. En muchos de los casos más emblemáticos, la justicia transicional se manifestó como una respuesta, sobre todo posterior, a una gran transformación política previamente acordada", (Lyons, p. 15) en consecuencia justicia transicional es una justicia producto de a un acuerdo entre partes, de un pacto de naturaleza política y por ende desde el punto de vista teórico, conveniente para todos. Se dice teórico en vista de que paradójicamente, en otros países si creen en el proceso de paz colombiano y en la necesidad y urgencia de su implementación.

\section{LaONUdefinelajusticiarestaurativaencualquiera} de los escenarios que en Colombia se puede aplicar, es decir, por medio del derecho penal, más concretamente del derecho procedimental penal, como: "un proceso para resolver el problema de la delincuencia enfocándose en la compensación del daño a las víctimas, haciendo a los delincuentes responsables de sus acciones y también, a menudo, involucrando a la comunidad en la resolución del conflicto. La participación de las partes es esencial al proceso y enfatiza la construcción de relaciones y reconciliaciones, así como el desarrollo de acuerdos en torno a un resultado deseado por las víctimas y los delincuentes. Los procesos de justicia restaurativa pueden adaptarse a varios contextos culturales y a las necesidades de comunidades diferentes. A través de ellos, el proceso en sí mismo a menudo transforma las relaciones entre la comunidad y el sistema de justicia como un todo" (Oficina de las Naciones Unidas contra la Droga y el Delito, 2006).

Para la ONU la justicia restaurativa tiene entre muchas otras características el ser "una respuesta flexible a las circunstancias del delito, el delincuente y la víctima que permite que cada caso sea considerado individualmente; este aspecto es bien importante si se considera que en este modelo de justicia no hay penas como tal y que se busca es una salida negociada al conflicto que deriva de la infracción a la ley penal. (Oficina de las Naciones Unidas contra la Droga y el Delito, 2006).

Para la Corte Constitucional en Sentencia C 112 del 2019 la justicia transicional es "una institución jurídica "...constituida por un conjunto de procesos de transformación social y política profunda en los cuales es necesario utilizar gran variedad de mecanismos para resolver los problemas derivados de un pasado de abusos a gran escala, a fin de lograr que los responsables rindan cuentas de sus actos, servir a la justicia y lograr la reconciliación. (Corte Constitucional. Sentencia C 112, M.P. José Fernando Reyes Cuartas, Bogotá D.C., trece (13) de marzo de dos mil diecinueve (2019).

En virtud de aplicar justicia restaurativa esta se confunde con la justicia de transición, la que según la Corte Constitucional en sentencia $C$ 007 del 2018 tiene como principales propósitos: "(i) responder a la violencia generalizada y, por ende, asegurar el derecho a la paz; (ii) garantizar los derechos de las víctimas a la verdad, la justicia, la reparación y la no repetición de los hechos violentos; (iii) fortalecer al Estado de 
derecho y a la democracia; y (iv) promover la reconciliación social" (Corte Constitucional Sentencia C-007/18, M.P. Diana Fajardo Rivera).

En esa perspectiva, si lo que se desea es instaurar un enfoque restaurativo a gran escala se requiere de una política criminal específica para procesos de transición, como resalta Uprimny "una política criminal en tiempos de transición debe tener muy clara su relación con la política de rendición de cuentas; debe tener una estrategia clara; debe velar por que las iniciativas cuenten con la capacidad y las competencias técnicas requeridas para investigar y enjuiciar esos crímenes; y debe prestar particular atención a las víctimas" (Uprimny, p. 38) este último aspecto es importante en la medida en que las víctimas son parte fundamental de un proceso de esta naturaleza y en la medida en que las víctimas sean realmente tenidas en cuenta las posibilidades de reconciliación nacional se aumentan.

Debiera ser fácilmente comprensible que para superar años e incluso décadas de conflicto armado y por supuesto de masivas y graves violaciones a los Derechos Humanos, la única manera de terminar con esa atroz guerra es tomar una serie de medidas por medio de las cuales intentar superar las consecuencias del conflicto, pero como se verá en este artículo las dificultades son demasiadas, especialmente por la carencia de voluntad política del gobierno actual.

\section{EL PROCESO DE PAZ EN \\ COLOMBIA.}

El tema de la violencia generalizada producto del conflicto es resuelto por quienes intervienen en el proceso de negociación del Acuerdo de Paz, a través una transacción, en la que se prescinde de los enfrentamientos armados y acuerdan toda una serie de pasos encaminados a evitar que se vuelva a la contienda militar, estos son de naturaleza eminentemente política. Es decir, los efectos de la justicia de transición son políticos, enmarcados dentro de la democracia. En torno al tema, el profesor Valencia Villa considera que para poder superar "un pasado de atrocidad e impunidad, y hacen justicia a las víctimas de dictaduras, guerras civiles y otras crisis de amplio espectro o larga duración, a fin de alcanzar o retornar a una normalidad democrática" (Valencia Villa, 2007 , p.1) se tiene que llevar a cabo una justicia transicional en la que se utilicen diferentes mecanismos que permitan la superación del conflicto armado.

Luego de muchos y vanos intentos de diferentes gobiernos por derrotar a su principal enemigo las Farc-Ep grupo guerrillero violento que ocasionó muertes, desapariciones y desplazamientos forzados en casi todo el país. Por su parte este grupo tampoco logró tomarse el poder. Después de tantos avatares el logro de la paz era muy cercano a la sociedad colombiana. EI principal objetivo de la negociación de paz fue "dejar atrás un conflicto armado y reconstituir el tejido social, dicha transformación implica la difícil tarea de lograr un equilibrio entre las exigencias de justicia y paz, es decir, entre los derechos de las víctimas del conflicto y las condiciones impuestas por los actores armados para desmovilizarse". (Uprimny, 2017)

El ascenso a escenarios de violencia masiva y generalizada de los grupos paramilitares al finalizar el siglo anterior y al principio de este, exigió que se adelantar un "acuerdo" para desmantelar estos grupos, se pretendía que la ley 975 de 2005 expedida por el gobierno Uribe fuera una de las normas que teóricamente permitiría alcanzar la paz, lo que evidentemente no se logró. Ante esa situación de violencia llevada a cabo por diversos grupos criminales organizados, el país se planteó la necesidad de llegar una negociación con la guerrilla de las Farc-Ep. Recuérdese que en Colombia el conflicto armado interno, definió en buena medida lo que sería la trágica historia, por demás 
violenta, de un país signado a dar continuidad a ciclos violentos debido a su falta de buenos y duraderos procesos de transición en los que hubiese algo de justicia o de verdad.

Dentro de los intentos por lograr llegar a negociaciones con grupos armados ilegales el penúltimo de esos intentos se llevó a cabo, antes de alcanzar la instauración de la justicia transicional, se dio por medio de la Ley 975 de 2005.

Sin embargo, ni la ley 975 del 2005 ni ninguna de las anteriores formas de terminación de un conflicto o guerra permitió que se llegara a cambios que por mínimos que hubiesen sido, lo es que era claro habrían podido cambiar el rumbo de nuestro país. De la mano de procesos penales en su gran mayoría y otros pocos basados en justicia transicional se intentó judicializar al otro, al rival, al guerrillero, al paramilitar, al militar, al civil, pero poco o nada se hizo por llevar a cabo cambios sustanciales en la economía, cultura, educación y mucho menos se hizo una acérrima defensa de los derechos humanos y de los derechos de las incontables víctimas.

El Acuerdo de Paz era viable de conformidad con los tratados internacionales ratificados por Colombia, aunque internamente algunos grupos políticos hicieran una fuerte oposición, el apoyo internacional era importante y la voluntad del presidente Santos (2010-2014) era total para llegar a finiquitar el acuerdo.

Como concluyen Ciro y Ríos "los Acuerdos de Paz serían, en términos kantianos, una especie de "ley permisiva"; es decir, "vendría a contener la obligación de realizar un acto al que nadie puede ser obligado", pero ese carácter contradictorio no impide que sea «honesta» (Kant, 1795 2003). Así pues, "la generosidad" de un acuerdo de paz en cuanto a favorecer los intereses de todos los colombianos, un uno u otro sentido, es evidente. Deducen los mencionados investigadores que esta es una aspiración colectiva "un deseo de muchos sectores del pueblo y del establishment colombiano por avanzar hacia otro país, y no tanto como una derrota/victoria de uno de los adversarios." (Cairo y Ríos, 2019, p. 106- 107).

En razón a su autonomía, Colombia con el apoyo de países como Cuba y Noruega entre muchos otros, diseñó una justicia que permitiera enfrentar una enorme criminalidad a través de diversos métodos de justicia se ideó una justicia de transición basada en experiencias internacionales y muy seguramente en desaciertos internos. Es un tipo de justicia que tiene su asidero en el respaldo internacional a un proceso de paz y a la existencia de unos países que sirven de garantes al cumplimiento de los acuerdos. En esa justicia se tienen en cuenta estándares internacionales en materia de justicia respecto al DIH y a los DDHH. El llegar a tener unos acuerdos entre actores armados muy crueles como las Far Ep era una oportunidad única para evitar los rigores de la guerra, para evitar el sufrimiento a millones de víctimas y lograr, verdad, justicia, reparación y lo mejor la no repetición. Al cumplirse estos objetivos Colombia puede llegar a tener una paz estable y duradera.

Cuando se llevan a cabo procesos de transición de un medio hostil de guerra constante a una etapa de armonía que dé cabida a la calma fundamental para el desarrollo del país, es ahí donde la justicia transicional emerge en la búsqueda de la verdad. La verdad en la justicia transicional es el eje de todo el sistema.

Es a través de ese reciente modelo de justicia transicional que se llega a trazar una serie de acciones y programas que todo parece indicar van en el camino indicado por teóricos sobre los que debe ser una justicia que permita terminar con años de conflicto. El camino escogido fue un modelo de justicia transicional que no obstante la inexistencia de un solo canon de este tipo de justicia, la realidad es que en Colombia se acogió lo que se denomina como "el conjunto 
de medidas judiciales y políticas que diversos países han utilizado como reparación por las violaciones masivas de derechos humanos. Entre ellas figuran las acciones penales, las comisiones de la verdad, los programas de reparación y diversas reformas institucionales." (Centro Internacional para la Justicia Transicional) Y así, se llevan a cabo diversas formas de lograr la finalidad última de la justicia de transición, esto es el logro de una paz estable y duradera.

Actualmente, la implementación del acuerdo no es lo que se esperaba, ha dicho Baldosea que se espera se consolide "la necesaria materialización del andamiaje institucional que nace de dicho acuerdo y, en especial, de los instrumentos jurídicos que, en materia de justicia y reparación a las víctimas, se acojan bajo la mira de un modelo de justicia transicional, restaurativa y prospectiva." (Baldosea, p. 105)

\section{JUSTICIA TRANSICIONAL:}

\section{RESTAURATIVA Y JUSTICIA PENAL: RETRIBUTIVA.}

Con varios millones de víctimas del conflicto armado Colombia es un referente mundial en materia de la utilización de una justicia transicional que promete salvaguardar la ley y la Constitución.

Dentro de las características de la justicia de transición se encuentra el dialogo, el perdón la verdad y por supuesto la reparación a las víctimas, ahora bien, hay que evitar al máximo la colisión de derechos fundamentales y es de procurar la protección de los DDHH y al DIH y hay lugar al restablecimiento de controles constitucionales que permitan la satisfacción en materia de justicia de parte de la sociedad y es prioritario evitar la vulneración a derechos valiosos para el ser humano. Una de las consecuencias de una adecuada respuesta a los pedimentos de hacer justicia con los criminales que llevaron a cabo muchos crímenes es a través de esta justicia. De lograrse, el proceso de reconciliación nacional es efectivamente un logro nunca antes visto, es importante para superar situaciones de conflicto armado la cual surge a partir del reconocimiento del conflicto y es allí donde es importante que allá justicia y el establecimiento de un sistema de sanciones propio de la justicia restaurativa en el que especialmente debe existir no solo perdón si no un sistema de preceptos establecido para superar el conflicto en el que esas sanciones sean en la medida de lo posible no privativas de libertad. La reconciliación es una dimensión para superar el conflicto armado en el que el reconocimiento de la verdad permite una muy buena transición a la reconciliación del país y a la consolidación de la paz como derecho fundamental.

En este sentido Arango indica que "cuando la indignación logra canalizarse por vía de sanciones especiales y no simplemente por vía del castigo, el agresor puede sentir culpa y vergüenza, reconocer su actuar moralmente erróneo y verse motivado a cumplir las medidas restaurativas y reparadoras que permitan satisfacer los derechos de las víctimas." (Arango, 2019, p. 30)

Siendo el derecho penal basado en una justicia retributiva y la justicia transicional cimentada en justicia restaurativa lo que en principio pareciera modelos de justicia disimiles, de entrada, hay que señalar que ambos se complementan. Aspectos como autoría y participación; el cómo establecer la verdad; penas o sanciones; reparación a victimas perdones y castigos son ciertamente aspectos que atañen a ambos modelos de justicia.

Max Flórez señala dos aspectos importantes de la justicia restaurativa por un lado como una alternativa, y como forma de percepción, por supuesto que en Colombia es fundamental utilizarla. Destaca igualmente, que el objetivo es "fundar la convivencia en la reconciliación en términos de justicia y equidad, en medio de 
un océano de dudas y desconfianzas públicas sustentadas en el miedo al otro, a la obstinación frente a reconocer los errores y las faltas, al valor exclusivamente simbólico del perdón, y a la idea común de que solamente con la prisión se nivelan las cargas derivadas del daño que implica el delito". (Flórez, 2019, p. 39)

A pesar de lo dicho, el derecho penal se relativiza en medio de la justicia transicional, lo cual provoca tensiones ya que específicamente en la ley 975 de 2005, dice el profesor alemán Kai Ambos "por un lado, ella promueve una relativización especial del carácter racional de la persecución penal ligado a las máximas del Estado de Derecho. Por otro, estimula una disputa de los estándares ordinarios y mínimos de reprochabilidad que se plantean en la discusión y negociación de las contraprestaciones por desmovilización, desarme y reinserción. (Ambos, 2010, p. 3)

Daly viene a reconocer que los defensores de la justicia restaurativa incluyen en su discurso al menos cuatro mitos, el primero de ellos es que la justicia restaurativa es lo opuesto a la justicia retributiva; el segundo es que la justicia restaurativa utiliza prácticas de justicia indígena y fue la forma dominante de justicia premoderna; el tercero es que este modelo de justicia es la respuesta o femenina al crimen en comparación con una respuesta de "justicia" de tipo masculino; y por último que la justicia restaurativa produce cambios importantes en las personas. (Daly, 2002) Mitos o no la verdad es que en el caso colombiano justicia retributiva y restaurativa se complementan. Respecto a que fue y es utilizada por los indígenas para hacer justicia, esto es totalmente cierto. Que produce cambios en las personas vinculadas al proceso restaurativo y en la sociedad esto es evidente en lugares en donde se ha llevado este tipo de justicia. Con lo que no se puede estar de acuerdo es con que sea una justicia más para un género que para otro.
Las diferencias entre la justicia restaurativa y la retributiva dice Kathleen Daly radican en que la primera "se centra en reparar el daño causado por el delito, mientras que la justicia retributiva se centra en castigar un delito; la justicia restaurativa se caracteriza por el diálogo y la negociación entre las partes", (Daly, 2002).

Es fundamental que la sociedad tome conciencia acerca de las bondades de ese modelo de justicia para lograr que un modelo de justicia de esta naturaleza provoque las consecuencias esperadas. Además, es vital el establecimiento de unas normas al momento de la iniciación de la justicia transicional. Esto es que tienen que existir unas normas de carácter previo que le den validez y seguridad jurídica a ese modelo. Dichas normas en el caso colombiano se han establecido en el acto legislativo $01 \mathrm{del} 2017 \mathrm{y}$ en la ley 1957 del 2019 y otras normas que lo complementan que por medio del marco jurídico para la paz confeccionan la implementación de la justicia transicional" (p.104) a través de las cuales se determina fundamentalmente jurisdicción y competencia en general aspectos de tipo procedimental ante esa jurisdicción. Otras normas no se crean si no que se utilizan como parte fundamental del sistema, esto es las normas relativas al código penal colombiano. Pero aquí a pesar de tenerse en cuenta los tipos penales en su conducta no se tiene en cuenta la pena establecida en el estatuto penal ya que las normas ya referidas en el acto legislativo y en la ley aluden a un sistema de sanciones originales dentro de la justicia de transición nuestra.

\section{EL DERECHO PENAL EN LA JUSTICIA TRANSICIONAL.}

Es de resaltarse que dentro de este modelo de justicia también se tiene en cuenta el derecho internacional especialmente normas relativas al derecho penal internacional (DPI); al derecho internacional humanitario (DIH) y a los derechos humanos (DDHH) respecto de las cuales y de conformidad con el artículo 93 del a Constitución 
Nacional se emplean estas normas para evitar la vulneración a derechos fundamentales o a los DDHH. En esta dirección el derecho penal se tiene en cuenta la norma en su parte de la tipificación de la conducta punible pero no las penas allí consagradas.

Hay que subrayar que la función que cumple la fiscalía general de la nación, por ejemplo, respecto al iniciar la acción penal de imputar un delito, o acusar e inclusive de llegar a emitir una sentencia de carácter condenatorio no es incompatible con un modelo de justicia de transición. No hay ningún impedimento para que en cualquier momento de la actuación procedimental penal esta pueda pasar a la justicia transicional, como ya se ha recalcado ni siquiera una sentencia condenatoria ya que esta puede ser en un modelo de justicia de transición la sentencia condenatoria puede ser objeto de amnistías o de indulto. En este sentido el derecho penal viene a ser la base fundamental de la justicia transicional.

Las decisiones de la Jurisdicción especial para la Paz (JEP) deben comprender la ley interna y las internacionales, tanto en la jurisprudencia como en la doctrina. Todo esto significa que hay que adecuar el derecho nacional y su jurisprudencia, claro está respetando la autonomía y la soberanía nacional se tiene que adecuar la norma interna e internacional a un modelo de justicia transicional único, exclusivo, y propio de un contexto como el colombiano.

En aplicación del derecho penal ordinario y ahora en la justicia de transición han sido tradicionales tanto la amnistía como el indulto como formas de evitar la acción o la pena impuesta, y en la justicia de transición no son la excepción como mecanismos que en igual sentido son utilizados con frecuencia para superar los conflictos.

En Colombia hoy se brindan amnistías a los exintegrantes de la guerrilla de las Farc, aunque son cuestionados, ya que son percibidos como un monumento a la impunidad. Como dicen Uprimny, Saffon y Botero "los cuestionamientos políticos y éticos que surgen frente a una transición fundada en perdones "amnésicos", consistentes en las presiones nacionales e internacionales en contra de la impunidad de crímenes atroces, por un lado, y en el indeseable sacrificio de los derechos a la verdad y a la reparación de las víctimas de dichos crímenes, por otro. En ambos casos se parte de la base de que el perdón y el olvido de crímenes de tal naturaleza impiden una reconciliación nacional verdadera y durable, pues constituyen un germen de violencia futura." (Uprimny, p. 2526). Esta apreciación no debiera surtir mayores efectos al tratarse del logro de reconciliación y paz.

Para la Corte Constitucional el debido proceso es esencial no solo en la justicia ordinaria si no igualmente en la justicia transicional ya que la practica oportuna de pruebas y la posibilidad de contradecirlas y complementarlas, son elementos inseparables al derecho de defensa y "mayormente si se trata de un contexto como el actual, que exige que aun los jueces creados para la transición sean jueces constitucionales, dispuestos a enfrentar en un marco de esa naturaleza -constitucional- la forma de superar, con verdad, justicia, reparación y no repetición, las condiciones históricas de violencia y exclusión, todo ello con el uso de herramientas ingeniosas de acción" (Corte Constitucional Sentencia C 112 del 2019, M.P. José Fernando Reyes Cuartas).

Conviene dimensionar la fundamentación de la justicia transicional en cuanto a un amplio abanico de estrategias para solventar el grave problemas de impunidad, de la masividad de los delitos, y del enorme número de autores o participes que han estado vinculados a procesos penales. Por estas razones en opinión de Torres se debe acudir a instrumentos internacionales 
donde se "tenga en cuenta los incontables factores que intervienen en la comisión de conductas punibles, determinar los más básicos lineamientos dogmáticos que conlleven como establecer la responsabilidad penal individual, y como evitar impunidad frente a graves crímenes ocurridos en un conflicto armado, es decir, como lograr compatibilizar el castigo a la criminalidad a gran escala en medio de una justicia transicional, que por supuesto tiene otros fines". (Torres, 2018, p. 140)

Es evidente que para tales propósitos se tenga en cuenta la legalidad "ya que, al actuar bajo el imperio del principio de legalidad, se evita, por un lado, aplicaciones o adecuaciones típicas restringidas o amplias y sobre todo la ambigüedad en la interpretación y por el otro, no quedan dudas acerca del apego a la Constitución, la ley y el derecho penal internacional." (Torres, 2018, p. 141)

La Corte Constitucional en sentencia C 112 del 2019 ha expresado que la justicia transicional se diferencia de los procesos penales y sancionatorios ya que tiene por objeto "lograr la judicialización y terminar así -ciertamente, con ciertos sacrificios- las caóticas realidades sociales de conflictos, violencia y violaciones masivas de derechos humanos" (Corte Constitucional Sentencia C 112 del 2019, M.P. José Fernando Reyes Cuartas).

Cuando se lleva a cabo justicia retributiva, que como se ha dicho, es pieza básica y esencial de la justicia transicional en Colombia las penas pierden relevancia, ya que se utiliza un sistema de sanciones donde la perdida de la libertad es una enorme excepción, en donde la consecución de la libertad está ligada a dos momentos el primero de ellos a que se pertenezca a las Farc-Ep, a la fuerza pública o sea un tercero civil, es decir, cualquiera de los que el acto legislativo 01 del 4 de abril de 2017 señala su competencia respecto de conductas criminales efectuadas antes del 1 de diciembre de 2016 y las que tengan relación o en ocasión del conflicto armado interno. Un segundo momento hace énfasis en que quien quiera ser beneficiado con este tipo de justicia debe señalar la verdad y en esa proporción obtiene la libertad o ante la comisión de condutas criminales no ir a prisión.

En este sentido la revelación de la verdad como el gran componente de la justicia de transición hace parte de una visión moderna de superación no solamente de un conflicto si no de una forma de hacer justicia basada en la verdad.

El auténtico proceso de paz y reconciliación, que busca la reconstrucción del país, debe contener un componente de derecho penal mínimo y unos enormes mecanismos que concretamente estén destinados a la utilización de un modelo de justicia restaurativa que consolide la transición de la guerra a la paz.

\section{LA VERDAD COMO FORMA DE REPARACIÓN EN LA JUSTICIA TRANSICIONAL.}

Un modelo de justicia transicional se fundamenta particularmente en la verdad y a través de soluciones negociadas con un espíritu no vengativo una de sus finalidades ultimas es la reconciliación nacional, o al menos de gran parte de la misma. Siendo pues justicia restaurativa la que se impone al tenerse en cuenta la dimensión de un conflicto armado no internacional que desbordó la capacidad de asombro y disparó todas las cifras sobre víctimas en un conflicto armado como el colombiano.

En cualquiera de las formas de búsqueda de reparación: la propia del sistema penal o bien a través de la justicia de transición del Acuerdo de $\mathrm{Paz}$, la víctima que en Colombia sufrió los rigores del conflicto armado puede encontrar validas soluciones al daño ocasionado. Para Corte Constitucional en Sentencia C-538 del 2019, el derecho de reparación comprende un conjunto de medidas en el cual las víctimas tienen 
como garantía además del proceso judicial la: "(i) de restitución, (ii) de indemnización, (iii) de rehabilitación y (iv) de satisfacción. Conforme a lo sostenido en los Principios y directrices básicos sobre el derecho de las víctimas de violaciones manifiestas de las normas internacionales de derechos humanos y de violaciones graves del derecho internacional humanitario a interponer recursos y obtener reparaciones, la reparación debe ser adecuada, efectiva y rápida. (Corte Constitucional, Sentencia C-538, M.P. Diana Fajardo Rivera. 13/11/2019).

Como resultado de la puesta en marcha de la justicia transicional se han venido a dar reconocimientos especiales a las víctimas, y un enfoque de género que supone estar acorde con la sentencia T-718/17 donde la Corte Constitucional señala que la violencia sexual contra las mujeres no es solamente una discriminación social e histórica sino una forma de violencia de género en consecuencia son sujetos de protección constitucional reforzada. (Corte Constitucional, Sentencia T-718/17 M. P. Alejandro Linares Cantillo). En igual sentido, se tendrá en cuenta el enfoque diferenciado, esto es dar a un especial tratamiento de protección a los derechos de "las víctimas mujeres, niñas y niños, quienes sufren de una manera desproporcionada y diferenciada los efectos de las graves infracciones y violaciones cometidas con ocasión del conflicto." (Ley 1957 de 2019, artículo 18).

Como ya se dijo la justicia de transición es producto del Acuerdo de Paz y de allí se creó el Sistema Integral de Verdad, Justicia, Reparación y no Repetición, (SIVJRNR). De igual modo establecieron varios mecanismos en la búsqueda de la consolidación de la paz estable y duradera, así se crearon la Jurisdicción Especial para la Paz, Comisión de la Verdad y la Unidad de Búsqueda de personas desaparecidas.
Una de las características esenciales y definitorias del SIVJRNR ha conceptuado la Corte Constitucional en sentencia C 007 del 2018 es "la creación de un sistema propio de sanciones (propias, alternativas y ordinarias), que aplican a todos quienes, estando dentro del ámbito de competencia de la JEP, reconozcan su responsabilidad o sean hallados responsables de cualquier delito cometido por causa, con ocasión o en relación directa o indirecta con el conflicto armado" (Corte Constitucional colombiana. Sentencia C007, Magistrada Ponente Diana Fajardo Rivera, Bogotá, D.C., primero $\left(1^{\circ}\right)$ de marzo de dos mil dieciocho (2018).

Padilla reconoce como los principales elementos de la justica transicional: "i) un compendio de mecanismos judiciales y extrajudiciales excepcionales y transitorios; ii) se provee en el tránsito de una sociedad autoritaria a una sociedad democrática o a la finalización de un conflicto armado; iii) su finalidad es garantizar los derechos a la justicia, la verdad, la reparación integral a las víctimas y la no repetición." (Padilla, 2016, p. 242.)

Según Ríos Martín la justicia restaurativa forma parte de una justicia negociada en donde la víctima es de significativa importancia ya que: "parte de la víctima y de sus intereses, pero los hace confluir con los del infractor y con los de la comunidad; la paz y el diálogo social que el delito quebró serán así restablecidos y saldrá fortalecida la vigencia de la norma. La Justicia Restaurativa apela, pues, "a lo mejor" de cada ser humano, también del infractor, al que invita a reconocer la verdad, a hacerse responsable de sus consecuencias, a abandonar un estilo de vida poco respetuoso con el prójimo (aunque sea consecuencia de una historia de desatención y carencias) y a alcanzar autonomía y respeto a las normas de convivencia social. En términos de invitación, no de imposición" (Ríos 2016, p. 124). 
Al respecto Sánchez y Parra, controvierten la expresión general en cuanto a que la JEP es "un "sistema penal especial" o como un "mini-sistema de Roma" o "mini-Corte Penal Internacional". En nuestra opinión estas dos visiones resultan reduccionistas de las potencialidades que puede - y debería - tener este sistema de justicia." (Sánchez y Parra, 2018, p. 68)

Conforme jurisprudencia de la Corte Constitucional la justicia transicional "constituye un conjunto de mecanismos que no obedecen a fórmulas rígidas, sino que deben atender las características de cada contexto histórico, geográfico, político y social, así como a las particularidades de cada momento de transición. Esta característica de ese especial tipo de institucionalidad permite que las partes en una negociación puedan contar con un amplio conjunto de herramientas para alcanzar el cese de las hostilidades y la reconciliación". (Corte Constitucional colombiana. Sentencia C007, Magistrada Ponente Diana Fajardo Rivera, Bogotá, D.C., primero $\left(1^{\circ}\right)$ de marzo de dos mil dieciocho (2018).

\section{LOS TROPIEZOS ENTRE LA TRADICIONAL JUSTICIA RETRIBUTIVA Y LA JUSTICIA TRANSICIONAL.}

La justicia retributiva se concibe como ligada al derecho penal, ya que así lo determina el artículo 4 del código penal y lo establece jurisprudencia y doctrina. En este sistema el juez es protagonista principal, el cual al lado del fiscal cumplen la función de hacer justicia y el centro de atención está en el infractor de la ley penal. Como bien indica Fuentes el derecho penal actúa "ante un mal como es el delito, se responde con otro mal, la pena, y entre estas dos razones rige una relación que por un arcano y profundo sentido de justicia exige la presencia de una cierta igualdad o equivalencia. De este modo, el componente retributivo vendría a configurarse como "el alma de la pena". (Fuentes, 2008, p. 2)
Álvaro Márquez destaca que en la justicia retributiva se fundamenta en la pena y que "en esta justicia el delito es un problema entre el Estado y el delincuente, sin en que ella la víctima, su familia o la comunidad puedan participar activamente aun cuando puedan estar interesados en la búsqueda de la solución generada con el delito". (Márquez, 2007, p. 204)

La importancia de la pena satisface un deseo vengativo que la sociedad exige a sus gobernantes y estos al legislador y de la cual no se puede sustraer el aplicador de justicia penal. En este punto, Fuentes recordando a Garrido señala que "la pena constituye, de este modo, una retribución que la sociedad impone por el mal causado de modo que: a mayor mal, mayor culpabilidad, y por lo tanto mayor castigo merece el culpable" (Fuentes, 2008, p. 13).

En el sistema retributivo la víctima no es precisamente el centro de atención, así, por ejemplo, la Corte Constitucional, al respecto ha dicho que "el protagonismo en un proceso judicial de tendencia retributiva lo adquiere el agresor y quien imparte o administra el sistema de justicia, en el caso de Colombia los Jueces de la Republica" (Corte Constitucional colombiana, Sentencia C-328/16, Magistrada ponente Gloria Stella Ortiz Delgado, 22 de junio de 2016).

En aplicación de la justicia transicional se utilizan múltiples instrumentos jurídicos y programas del gobierno que tienden a darle solidez a los acuerdos y al logro de paz estable y duradera. Se confunden así el derecho penal y la justicia retributiva con la justicia transicional y restaurativa.

En ese trasegar, concurren tensiones ya que compatibilizar dos modelos de justicia no es tarea fácil, estas salidas "negociadas" tienen que ser consensuadas de conformidad con la ley y con las particularidades del conflicto que se suscita en materia penal, ya sea con en aplicación de justicia restaurativa o retributiva tenido en cuenta 
que un delito como el narcotráfico es trasversal en la historia del conflicto armado colombiano. Otro importante logro ha sido la ley 1448 de 2011 (ley de víctimas y de restitución de tierras) la que ha permitido que tanto en un modelo de justicia o en otro se lleven a cabo restitución de tierras y especialmente con fundamento en esa ley se haga el reconocimiento de víctimas, aspecto que está ligado las posibilidades de alcanzar la paz.

Nuestra Corte Constitucional en sentencia C-370 de 2006, determinó la constitucionalidad de algunos de los artículos de la aludida ley (975 de 2005), ahora bien, esta ley diseñada inicialmente para el desmantelamiento de grupos de paramilitares, no contiene un código de procedimiento ante alguna jurisdicción específica, se fundamenta en el código penal y de procedimiento penal, pero si establece reducciones drásticas de pena a quien se acoja a esa ley. La corte señaló "Aún en el marco de un instrumento que invoca como propósito fundamental la materialización de la paz en el país, la pena no puede ser despojada de su atributo de reacción justa y adecuada a la criminalidad, ni puede producirse al margen de las intervenciones estatales que el ejercicio del ius puniendi reclama en el Estado constitucional de derecho. Lo primero conduciría a fenómenos de impunidad indeseables, aún en el contexto de un proceso de pacificación, y lo segundo a la pérdida de legitimidad de la potestad sancionadora del Estado. El régimen punitivo que caiga en uno $u$ otro fenómeno resulta contrario a la Constitución". (Corte Constitucional, Sentencia C-370 de 2006).

Las críticas a este prototipo de justicia han sido vertidas desde muchos ángulos, sin embargo, si ha sido patente su ineficacia y obsolescencia, son múltiples los aspectos que se tiene en cuenta como el escaso número de sentencias emitidas (47) en las que se condenaron a 195 postulados, tan sólo un $8,2 \%$ de los aspirantes a los beneficios de la legislación especial.
(Periódico el universal, 2017)

\section{LAS CARACTERÍSTICAS DE LOS CRÍMENES INTERNACIONALES DE COMPETENCIA DE LA JUSTICIA RESTAURATIVA Y DE LA JUSTICIA RETRIBUTIVA.}

El fin último de la justicia transicional es conocer la verdad dentro de un gran fenómeno de criminalidad definida como violenta por décadas. En ese escenario la prioridad tanto para la justicia penal ordinaria como de la justicia transicional es la persecución de conductas punibles denominadas graves crímenes internacionales.

Como afirma Carla Martini "los crímenes internacionales son de naturaleza colectiva, es decir, no pueden ser cometidos únicamente por un solo individuo, sino que involucran a varias personas que asumen distintos roles y actúan en función de diferentes motivaciones. Los autores de estos crímenes forman parte de una estructura o aparato, y actúan con el conocimiento de integrar ese aparato con un propósito común", (Martini, 2020, p.86) esta particularidad se encuentra presente en los crímenes cometidos en Colombia. En efecto, las condenas en la justicia ordinaria a integrantes de las Farc Ep, de agentes del Estado, y de muchos integrantes de organizaciones criminales pertenecientes a grupos de delincuencia común y otros tantos de la organizada. Se recalca que hasta ahora existe una alta impunidad en especial en los crímenes que quienes los cometen pertenecen a elites de poder o una posición destacada en la sociedad, en los que el denominador común es la convergencia de corrupción e impunidad. La masividad de estos crímenes es abordada ahora en la justicia transicional y con su componente de justicia restaurativa se espera se haga justicia.

La justicia transicional tiene un enorme componente de justicia restaurativa la cual es totalmente necesaria en un contexto en el que ha habido largos periodos de violencia como es 
el colombiano. Nuestra Corte Constitucional al respecto señala que la justicia transicional es: "un conjunto amplio de procesos y mecanismos, judiciales y no judiciales, de carácter excepcional y transitorio, que responden a largos periodos de violencia generalizada, en los que se han cometido constantes violaciones de derechos humanos y al derecho internacional humanitario". (Corte Constitucional Sentencia C-007/18, M.P. Diana Fajardo Rivera, Bogotá, D.C., primero $\left(1^{\circ}\right)$ de marzo de dos mil dieciocho (2018).

Como bien expresa el profesor Kai Ambos, "las expectativas adheridas a los resultados de la justicia transicional se centran básicamente en la concreción seria de investigaciones y juicios que permitan el desenlace no solo del factor retributivo del deber de persecución, sino también, del objetivo de restauración plasmado en los derechos de las víctimas dentro del contexto de transición." (Ambos, 2010, p. 2). Esto implica también el castigo a crímenes de lesa humanidad. Hay lugar también ha destacar que conductas consideradas muy graves como las de lesa humanidad, por ejemplo, son analizadas dentro de la justicia transicional en virtud del principio de favorabilidad con lo cual estas pueden ser objeto dentro de una interpretación teleológica y no exegética de aplicar justicia transicional con lo que las posibilidades de evitar el castigo a las mismas son muy amplias. No obstante, mientras se logre el no volver a cometer conductas criminales por parte de los beneficiados, se debe facilitar su proceso de reintegración y resocialización de tal manera que se avance en el logro y consolidación de la paz. En delitos de esta índole la justicia transicional cumple importantes fines para la sociedad y el futuro de Colombia, por este camino se podrá conocer la verdad de innumerables delitos , como por ejemplo los falsos positivos que como dice el profesor Torres son homicidios en persona protegida y "algunas (sino todas), las conductas caracterizadas como homicidios en persona protegida acaecidas en Colombia pueden fácilmente ser tipificadas como delitos de lesa humanidad, ya que estas acciones cumplen claro está con los requisitos señalados en el artículo 7.1 del Estatuto de Roma" (Torres, Huertas, Diaz, 2020, p. 174). Lo que permite concluir que de no hacerse justicia en Colombia a partir de conocer la verdad de lo ocurrido la Corte Penal Internacional podría entrar a tener competencia sobre esas conductas.

\section{CONCLUSIONES.}

A partir del Acuerdo de Paz nace la justicia de transición o justicia transicional con su gran componente la justicia restaurativa.

Habría que destacar que todos los intentos para terminar el conflicto armado y alcanzar la ansiada paz han sido en vano, la imposibilidad de creación de acuerdos y un espíritu vengativo por parte de dirigentes políticos en décadas no permitió una solución ni al conflicto armado, ni al político, ni al social entre muchos otros. Todo lo cual contribuyó a un empobrecimiento y a una diferenciación social muy importante. Cualquier intento por lograr paz debe partir de buscar las causas que provocaron la violencia en Colombia, estas seguramente son la injusticia social y la inequidad, la pobreza etc., todo lo cual requiere de una enorme voluntad política y de consenso nacional en la búsqueda de la solución.

El actual desarrollo del proceso de paz, no siendo el mejor, permite ser optimista, un aspecto valioso en el Acuerdo de Paz es que este acogió elementos del Derecho Internacional, especialmente del DIH y de los $\mathrm{DDHH}$, lo que admite que el desarrollo de la justicia en Colombia sea acorde con estándares internacionales de justicia penal.

El Acuerdo de Paz ha sido el punto de partida en el que se subraya la inclusión de las víctimas y especialmente de las mujeres rurales a las que se les ha venido a brindar la reparación al daño causado. En igual sentido el proceso de 
paz ha servido para la reivindicación social de su género.

Se puede afirmar que el modelo de justicia transicional que actualmente opera en Colombia es la mejor opción, que, aunque la verdad, la justicia o la reparación que se logre sea mínima. Se ha ganado muchísimo con que no haya repetición, con que no ocurran conductas como desplazamientos forzados, masacres, etc., por parte de los actores que firmaron el Acuerdo de Paz, estos crímenes pararon con la firma del acuerdo, este es un efecto muy importante después de décadas caracterizada por la violencia en Colombia. Martín afirma que la reparación tiene que ser un "conjunto de acciones destinadas a restituir los derechos de las víctimas y proporcionar a los beneficiarios suficientes elementos para mitigar el daño producido por las violaciones, promover su rehabilitación y compensar las pérdidas" (Martín, 2008, p. 14).

Es fundamental poner en marcha toda una estrategia de construcción de paz, lo que hasta ahora no ha sido posible debido a intervención de partidos políticos que consideran la guerra como su principal fuente de votos. Por lo tanto, sigue quedando en duda la política del gobierno Duque respecto al SIVJRNR; lo que si queda claro es que en Colombia el modelo de justicia de transición es un importante paso a la realización, consolidación y permanencia de una paz necesaria después de años de conflicto.

El Estado debe propender un sistema mediante el cual se utilicen y privilegien mecanismos de justicia restaurativa y en los que se deje en un segundo plano el clásico tratamiento penal con sus penas como el principal aleccionador de la sociedad. Tanto justicia transicional como retributiva la propia del derecho penal son necesarias de aplicación para romper los ciclos de violencia en Colombia.

Ante las intensas y violaciones a los derechos humanos en Colombia sucedida durante casi un siglo, el empleo de justicia transicional con su gran componente de justicia restaurativa y con la reforma institucional, el apoyo internacional y la voluntad política interna se puede esperar que haya una verdadera reconciliación nacional que permita unos grandes avances en todo el Estado y la sociedad colombiana.

La corrupción generalizada en Colombia y la no aplicación de justicia ha ido en paralelo al narcotráfico el cual ha alimentado todos los actores de la guerra en Colombia. No obstante, ha venido creciendo el espectro de cultura en muchos ámbitos y de manera trasversal existe un enfoque de la importancia y defensa de los DDHH que irradia las decisiones de las altas cortes y de la Jurisdicción Especial para la Paz.

Se concluye que el derecho penal está incorporado simbióticamente a la justicia de transición en procura de evitar en la medida de lo posible visos de impunidad, cuestión está respecto de la cual tradicionalmente en Colombia han existido voces que disienten del modelo de justicia.

\section{REFERENCIAS BIBLIOGRÁFICAS}

Acto legislativo 01 del 4 de abril de 2017.

Ambos, K. (2008) El marco jurídico de la justicia de transición. Especial referencia al caso colombiano, Editorial Temis, Bogotá,

Ambos, K. (2010). Procedimiento de la ley de justicia y paz (Ley 975 de 2005) y derecho penal internacional. Estudio sobre la facultad de intervención complementaria de la Corte Penal Internacional a la luz del denominado proceso de "justicia y paz" en Colombia.

Arango. R. (2019) Justicia transicional, emociones morales y reconciliación social: un frágil equilibrio, en: Rojas, D. editor, La JEP vista por sus jueces (2018-2019) Jurisdicción Especial para la Paz. 
Baldosea, H. Una aproximación a la construcción del régimen de condicionalidad en la Sala de Definición de Situaciones Jurídicas, en: Rojas, D. editor, La JEP vista por sus jueces (20182019) Jurisdicción Especial para la Paz.

Cairo, H., \& Ríos, J. (2019). Las élites políticas y la paz territorial en Colombia: un análisis de discurso en torno al Acuerdo de Paz. Revista Española de Ciencia Política, (50), 91.

Cárdenas, Á. E. M. (2007). La justicia restaurativa versus la justicia retributiva en el contexto del sistema procesal de tendencia acusatoria. Prolegómenos, 10(20), 201-212.

Corte Constitucional Sentencia C-007/18, M.P. Diana Fajardo Rivera, Bogotá, D.C., primero $\left(1^{\circ}\right)$ de marzo de dos mil dieciocho (2018).

Corte Constitucional, Sentencia C-538, M.P. Diana Fajardo Rivera. 13/11/2019.

Corte Constitucional, Sentencia T-718/17 M. P. Alejandro Linares Cantillo

Corte Constitucional. Sentencia C 112, M.P. José Fernando Reyes Cuartas, Bogotá D.C., trece (13) de marzo de dos mil diecinueve (2019).

Daly, K. (2002). Restorative justice: The real story. Punishment \& Society, 4(1), 55-79.

De Greiff, P. (2012) Theorizing Transitional Justice, en: WILLIAMS, Melissa / NAGY, Rosemary / Elster, Jon: Transitional Justice, New York University Press, Nueva York,

Flórez M. (2019) Justicia restaurativa y proceso penal. rama judicial. Consejo superior de la Judicatura.

Forer, Andreas: Justicia Transicional, Editorial Ibáñez, Bogotá, 2012, 19.

Fuentes Cubillos, H. (2008). El principio de proporcionalidad en derecho penal: Algunas consideraciones acerca de su concretización en el ámbito de la individualización de la pena. lus et Praxis, 14(2), 13-42.

Ley 1957 de 2019.

Ley 1957 del 2019.

Londoño H. (2012), Lecciones de Derecho Penal, Procedimiento Penal y Política Criminal, Biblioteca Jurídica Diké.

Lyons, Amanda (2010) Colombia: hacia una transición justa Amanda Lyons en: Transiciones en contienda: disyuntivas de la justicia transicional en Colombia desde la experiencia comparada / Centro Internacional para la Justicia Transicional (ICTJ).

Márquez Cárdenas, A. E.; (2007). La justicia restaurativa versus la justicia retributiva en el contexto del sistema procesal de tendencia acusatoria. Prolegómenos. Recuperado de http://www.redalyc.org/pdf/876/87602012.pdf

Martini Claudia, (2020). La teoría del dominio del hecho y la empresa criminal conjunta en el derecho internacional penal: desencuentros en torno al derecho aplicable en los modos de atribución de responsabilidad individual, en: Natalia M. Luterstein (editora) El derecho aplicable por los tribunales penales internacionales. Universidad de Buenos Aires. Facultad de Derecho. Secretaría de Investigación. Departamento de Publicaciones.

Oficina de las Naciones Unidas contra la Droga y el Delito. Sobre programas de Justicia Restaurativa, (2006). Recuperado de: https://www.unodc. org/documents/justiceandprisonreform/Manual_sobre__ programas_ de_justicia_restaurativa. pdf.

Orozco, Iván. 2009. Justicia transicional en tiempos del deber de memoria. Bogotá, Temis Universidad de los Andes.

Padilla, A. M. I. (2016). Justicia Transicional. Revista de Derecho, (45). 
Periódico "El Universal". Justicia y Paz costó $\$ 11$ billones, pero solo hay 47 sentencias, 23 de abril de 2017.

Ríos Martín, J. C. (2016). Justicia restaurativa y mediación penal.

Sánchez León, N. C., Parra Vera, O., \& Gómez Jaramillo, A. (2018). Elementos para una justicia de paz restaurativa. Ediciones USTA.

Torres Vásquez, H. (2013). La extraterritorialidad de la ley penal: el principio de justicia universal, su aplicación en Colombia. Prolegómenos, 16(31), 99-115.

Torres Vásquez, H. (2018). La responsabilidad por el mando en la justicia transicional colombiana. Revista Academia \& Derecho, 9(16), 137-162.

Torres, Huertas, Diaz, (2020) Homicidios en persona protegida: ¿una forma de terrorismo de estado democrático en Colombia? La reparación del daño en la justicia retributiva y en la restaurativa. Utopía y praxis latinoamericana. año: $25, N^{\circ}$ extra 8,2020 , pp. 165-182 Revista internacional de filosofía y teoría social cesafces-universidad del Zulia. Maracaibo Venezuela.

Uprimny, R., Saffon, M. P., Botero, C., \& Restrepo, E. (2006) ¿Justicia transicional sin transición? Verdad, justicia y reparación para Colombia (Centro de Estudios de Derecho, Justicia y Sociedad, DeJusticia, Bogotá.

Uprimny, Sánchez, Lozano (s.f.) Introducción al concepto de justicia transicional y al modelo de transición colombiano. Módulo de formación dirigida. Consejo Superior de la Judicatura Sala Administrativa Escuela Judicial.

Valencia Villa, H. (2007). Introducción a la justicia transicional. Cátedra Latinoamericana "Julio Cortázar" de la Universidad de Guadalajara (pp. 1-16). Guadalajara: Universidad de Guadalajara.
Yepes, U. Justicia transicional en perspectiva comparada: procesos transicionales, formas de justicia transicional y el caso colombiano. Recuperado de https://www. dejusticia. org/wpcontent/uploads/2017/04/fi_ name_recurso_53. pdf. 